\title{
Correction to: Relation of Superficial and Deep Layers of Delaminated Rotator Cuff Tear to Supraspinatus and Infraspinatus Insertions
}

\author{
Joongbae Seo ${ }^{1} \cdot$ Jongheon Yang ${ }^{1} \cdot \mathrm{Kang} \mathrm{Heo}^{1} \cdot$ Jae-sung Yoo ${ }^{1}$
}

Published online: 12 June 2020

(C) Indian Orthopaedics Association 2020

\section{Correction to: \\ Indian Journal of Orthopaedics (2020) 54:366-373 \\ https://doi.org/10.1007/s43465-019-00020-6}

The original version of this article unfortunately contains a mistake: The funding source is missing. The correct funding information is given below:

Funding The present research was supported by the research fund of Dankook university in 2019.

The original article can be found online at https://doi.org/10.1007/ s43465-019-00020-6.

Jae-sung Yoo

osarthro@gmail.com

1 Department of Orthopaedic Surgery, Dankook University

College of Medicine, Manghyangro 201, Dongnam-gu,

Cheonan, Chungnam 330-715, Republic of Korea 